Original Article

\title{
GLYCEMIC AND LIPIDEIC STATUS IN PATIENTS WITH ACUTE MYOCARDIAL INFARCTION
}

\author{
A. Harish Rao \\ Associate Professor, Department of General M edicine, \\ Srinivas Institute of M edical Sciences and Research Centre, M angalore, Karnataka, INDIA \\ Correspondence \\ A. Harish Rao \\ Associate Professor, Department of General M edicine, Srinivas institute of M edical Sciences and Research Centre \\ M angalore, Karnataka, India. M obile : +91 9845455766 E-mail: drharishrao@gmail.com
}

\begin{abstract}
:
Objective: to know the glycemic and lipidaemic status in patients with acute myocardial infarction, and with the secondary objective to know the effect of age, gender, diabetes, smoking, hypertension on fasting glucose and lipid levels.

Methods and materials: The 74 patients admitted for acute myocardial infarction during the study period of one year were analysed for fasting glucose values and serum levels of total cholesterol, HDLcholesterol, LDLcholesterol and triglycerides.

Results : The mean serum concentrations of total cholesterol, triglycerides, HDL cholesterol and LDL cholesterol were 233.28 \pm 45.34 , $139.22 \pm 41.71,171.43 \pm 36.53$ and $27.07 \pm 36.53$ respectively. M ean levels of total cholesterol, HDL cholesterol, triglycerides and fasting glucose values were not affected by age, gender, BMI, hypertension and smoking. BMI $>30 \mathrm{~kg} / \mathrm{m} 2$ was associated with increased levels of total cholesterol $(p=0.013)$ and $L D L$ cholesterol $(p=0.014)$. Also increase $L D L$ cholesterol was seen in male gender $(p=0.04)$. The prevalence of hypercholesterolemia, hypertriglyceridemia and low HDLcholesterol was $82.4 \%, 77 \%$ and $78 \%$ respectively. Diabetes had no effect on lipid profile.
\end{abstract}

Conclusion: our study highlighted the prevalence of dyslipidemias associated with myocardial infarction but not significant impact of fasting glucose levels.

Keywords: fasting glucose, lipidemic status, myocardial infarction, coronary heart disease

\section{Introduction:}

$80 \%$ of deaths due to cardiovascular disease occur in low and middle income countries. In developing countries, CVD represents $3 / 4$ of mortality from non-communicable diseases. ${ }^{1}$ CVD's cause 1.7-2.0 million deaths annually in India. ${ }^{2}$ By 2030 more than 23 million people will die annually from CVD's. ${ }^{3}$

Global prevalence of diabetes was estimated to be $10 \%$ and CVD accounts for about $60 \%$ of all mortality in people with diabetes. ${ }^{4}$ Diabetes Access this article online Quick Response Code

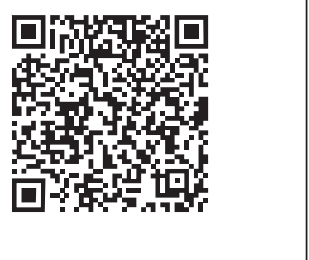
also is associated with numerous cardio vascular risk factors, and increased incidence of myocardial infarction and congestive heart failure. ${ }^{5,6}$ Women with diabetes seem to lose most of their inherent protection against developing CVD. ${ }^{7}$

Dyslipidemias are one of the major modifiable risk factor for coronary heart disease. ${ }^{8}$ Low HDL-C is the most common lipoprotein abnormality in patients with $\mathrm{CHD}$ and is predictive of $\mathrm{CHD}$ events even when total cholesterol levels are normal. Gupta R et al demonstrated a persistent high prevalence and increasing non-HDL cholesterol and Triglycerides over a period of 8 years. ${ }^{9}$ Clinical trials of lipid lowering agents have shown that modest increase in HDLcholesterol significantly reduces $\mathrm{CHD}$ event rates. ${ }^{10}$

Aims and objectives: The primary objective to know the glycemic and lipidaemic status in patients with acute myocardial infarction, and with the secondary objective to know the effect of age, gender, diabetes, smoking, hypertension on fasting glucose and lipid levels.

M aterials and M ethods: The present study was conducted in the department of cardiology, and medicine of K.L.E 's 
Hospital and M RC, Belgaum for a period of one year.

Selection of cases: Inpatients who met the following criteria were included in the study

1. Patients with history suggestive of acute myocardial infarction.

\section{ECG evidence of acute myocardial infarction}

3. Elevated levels of cardiac enzymes(CKM B, LDH, AST)

Total sample size as determined by the systematic sampling method was 74 .

The 74 patients who met the above said inclusion criteria were evaluated in detail regarding,

\section{Symptoms and signs}

2. Risk factors like smoking, alcohol, family history of CVD, type A personality, obesity ,hypertension, diabetes mellitus, lipid profile, lipoprotein (a),

3. Type of infarction

4. Course of hospital stay and complications

5. Mortality

Definitions in our study included,

Smoking: Patient who smoked more than 25 cigarettes per day wastaken as smoker

Hypertension: Was defined as persistent recording of blood pressure more than $140 / 90 \mathrm{mmh}$ according to Framingham heart study.

Diabetes Mellitus: Patients with FBS $>126 \mathrm{mg} / \mathrm{dl}$, PPBS $>200 \mathrm{mg} / \mathrm{dl}$. Patient at the time of diagnosis of DM or who require insulin therapy or oral drugs for the control of diabetes were said to be diabetics. ( AM ERICAN DIABETES ASSOCIATION, Standards of M edical Care in Diabetes 2013, DIABETES CARE, VOLUME 36, SUPPLEMENT 1, JANUARY 2013)

Obesity: Was considered the risk factor if the BM I exceeded $30 \mathrm{mg} / \mathrm{m} 2$. BMI was calculated by the formula,
Nitte University J ournal of Health Science

weight $(\mathrm{kg})$

Height $(m)^{2}$

Hypertriglyceridemia: Serum triglycerides level $>200 \mathrm{mg} / \mathrm{dl}$

Hypercholesterolemia: Serum total cholesterol level $>200 \mathrm{mg} / \mathrm{dl}$

Low HDL- Cholesterol: Serum HDL Cholesterol level< $40 \mathrm{mg} / \mathrm{dl}$

Blood collected for analysis within 24 hours of onset of acute myocardial infarction.

Enzymatic estimation of total cholesterol by CHOD - PAP method. Enzymatic estimation of serum Triglyceride using GPO - Kit method. Enzymatic estimation of High Density Lipoprotein using HDL-cholesteroldirect kit. LDL and VLDL are estimated using Friedewald formula.

\section{Methods:}

M ean values have been presented as mean(SD). Univariate and multivariate analysis was carried out using SPSS 16(statistical package for social sciences). The sample independent $t$ test was used to compare the statistical significance between continous variables(age, BMI). Chi square test was used to compare between categorical variable (gender, diabetes, hypertension, smoking). For comparison of lipid levels in young and older groups, the patients were divided into those above 50 years and below 50 years. A p value of $\varangle$.05 was considered significant.

Maximum incidence of myocardial infarction was seen in age group of $41-50$ years(36.4\%). The age group of 51-60 accounted for $22.9 \%$.

$75 \%$ of patients were males. M ale to female ratio was 2.9:1

The commonest presentation was typical history of chest pain with radiation and associated with sweating. $31 \%$ of our patients had anterior wall myocardial infarction and $29.7 \%$ had inferior wall myocardial infarction. Combination of infero lateral infarction was seen in $12.1 \%$ of patients.

47.2\% had ST segment elevation with T wave inversion . Q wave myocardial infarction was present in $28.3 \%$ of our 
patients.

85.1\% of patients recovered from the cardiovascular event.

$64.8 \%$ of them had complications during hospital stay. The most common was arrhythmias seen in $36.4 \%$ of patients.

Ventricular tachycardia was commonest arrhythmia seen. Others included cardiogenic shock(17.5\%), $\operatorname{LVF}(9.4 \%)$,complete heart block(5.4\%), papillary muscle dysfunction(1.3\%) and post infarction pericarditis(1.3\%).

Duration of hospital stay was 14 days. M ortality rate was $9.4 \%$ in our study.

$37.83 \%$ were obese $(\mathrm{BM} />30 \mathrm{~kg} / \mathrm{m} 2), 47.30 \%$ of patients were hypertensive, $45.95 \%$ diabetic with mean value of fasting glucose $133.46 \pm 59.54 \mathrm{mg} / \mathrm{dl}$.

Among the diabetics, $55.88 \%$ of patients had normal FBS,
Table 1: shows the demographic and clinical characteristics of the patients.

\begin{tabular}{|c|c|c|c|}
\hline \multicolumn{2}{|l|}{ Variable } & $\begin{array}{c}\text { Value } \\
\text { Mean(SD) }\end{array}$ & Frequency (\%) \\
\hline \multicolumn{2}{|l|}{ Age (years) } & $52.7(10.7)$ & \\
\hline \multirow[t]{2}{*}{ Gender } & male & $55(74.32)$ & \\
\hline & female & & $19(25.68)$ \\
\hline \multicolumn{4}{|l|}{$\mathrm{BMI}(\mathrm{kg} / \mathrm{m} 2)$} \\
\hline & $>30$ & & $28(37.83)$ \\
\hline \multirow[t]{2}{*}{ Hypertension } & yes & & $35(47.39)$ \\
\hline & no & & $39(52.70)$ \\
\hline \multirow[t]{2}{*}{ Diabetes } & yes & & $34(45.95)$ \\
\hline & no & & $40(54.05)$ \\
\hline \multirow[t]{2}{*}{ Smoking } & yes & & $38(51.35)$ \\
\hline & no & & $36(48.65)$ \\
\hline \multicolumn{2}{|c|}{ Fasting Glucose(mg/dl) } & 133.46(59.54) & \\
\hline \multicolumn{2}{|c|}{ Total cholesterol(mg/dl) } & $233.28(45.34)$ & \\
\hline \multicolumn{2}{|c|}{ Triglycerides (mg/dl) } & 139.22(41.71) & \\
\hline \multicolumn{2}{|c|}{ HDL cholesterol(mg/dl) } & $171.43(36.53)$ & \\
\hline \multicolumn{2}{|c|}{ LDL cholesterol(mg/dl) } & $27.07(36.53)$ & \\
\hline
\end{tabular}

Table 2: shows the effect of age, gender, BMI, diabetes, hypertension, and smoking on serum levels of lipids in AM I patients.

\begin{tabular}{|c|c|c|c|c|c|}
\hline \multirow[t]{2}{*}{\begin{tabular}{|l|} 
Factors \\
\end{tabular}} & \multirow[t]{2}{*}{ Numbers } & \multicolumn{4}{|c|}{ Lipid concentration (mg/dl) } \\
\hline & & Total cholesterol & HDL-cholesterol & LDL-cholesterol & Triglycerides \\
\hline \multicolumn{6}{|c|}{ Age (years) } \\
\hline$<0$ & 37 & $229.38(50.88)$ & $35.6(11.73)$ & $168.63(47.94)$ & $129.81(42.41)$ \\
\hline \multirow[t]{2}{*}{$>50$} & 37 & $232.22(49.72)$ & $35.68(8.37)$ & 169.68(33.89) & $146.24(42.41)$ \\
\hline & & $\mathrm{p}(0.808)$ & $p(0.974)$ & $p(0.914)$ & $p(0.098)$ \\
\hline \multicolumn{6}{|l|}{ Gender } \\
\hline Male & 55 & $35.60(11.75)$ & $35.64(9.6)$ & $176.53(33.97)$ & $144.58(7.85)$ \\
\hline \multirow[t]{2}{*}{ Female } & 19 & $35.68(8.37)$ & $35.00(10.36)$ & $156.68(40.51)$ & $135.65(43.64)$ \\
\hline & & $p(0.304)$ & $p(0.603)$ & $p(0.04)$ & $(p 0.569)$ \\
\hline \multicolumn{6}{|c|}{ BMI(mg/m2) } \\
\hline$>30$ & 24 & $212.84(63.25)$ & $35.68(10.14)$ & $154.52(47.02)$ & $141.51(7.85)$ \\
\hline \multirow[t]{2}{*}{$<30$} & 50 & $242.09(35.81)$ & $35.61(10.27)$ & $178.37(34.76)$ & $135.65(43.64)$ \\
\hline & & $(p 0.013)$ & $(p 0.976)$ & $p(0.014)$ & $p(0.694)$ \\
\hline \multicolumn{6}{|c|}{ Diabetes } \\
\hline Yes & 34 & $236.97(37.67)$ & $35.62(7.73)$ & $171.53(36.66)$ & $133.76(46.07)$ \\
\hline \multirow[t]{2}{*}{ No } & 40 & $230.15(51.24)$ & $36.30(11.29)$ & $171.35(36.89)$ & $143.85(37.58)$ \\
\hline & & $(p 0.523)$ & $p(0.767)$ & $\mathrm{p}(0.983)$ & $p(0.303)$ \\
\hline \multicolumn{6}{|c|}{ Hypertension } \\
\hline Yes & 35 & $230.29(47.73)$ & $35.54(7.87)$ & $171(30.61)$ & $148.31(37.9)$ \\
\hline \multirow[t]{2}{*}{ No } & 39 & 235.97(43.53) & $36.38(11.27)$ & 171.82(41.5) & $131.05(43.67)$ \\
\hline & & $p(0.593)$ & $p(0.714)$ & $p(0.924)$ & $p(0.075)$ \\
\hline \multicolumn{6}{|c|}{ Smoking } \\
\hline Yes & 38 & $235.97(49.51)$ & $36.08(10.55)$ & 177(32.99) & $147.03(44.71)$ \\
\hline \multirow[t]{2}{*}{ No } & 36 & $230.44(40.99)$ & $35.89(8.98)$ & $165(39.54)$ & $130.97(37.13)$ \\
\hline & & $p(0.604)$ & $p(0.934)$ & (p0.180) & $p(0.098)$ \\
\hline
\end{tabular}

Effect of age, gender, BM I, diabetes mellitus, hypertension and smoking on serum levels of lipids in AM I patients. 
Table 3 : Effect of age, gender, BMI, hypertension, and smoking on fasting glucose value

\begin{tabular}{|c|c|c|c|c|}
\hline \multirow[t]{2}{*}{ Factors } & \multirow[t]{2}{*}{ Numbers } & \multicolumn{2}{|c|}{ FBS } & \multirow[t]{2}{*}{$P$ value } \\
\hline & & Mean & SD & \\
\hline \multicolumn{5}{|c|}{ Age (years) } \\
\hline$<50$ & 37 & 145.27 & 71.70 & \multirow[t]{2}{*}{0.088} \\
\hline$>50$ & 37 & 121.64 & 41.96 & \\
\hline \multicolumn{5}{|l|}{ Gender } \\
\hline Male & 55 & 134.94 & 62.22 & \multirow[t]{2}{*}{0.718} \\
\hline Female & 19 & 129.15 & 52.28 & \\
\hline \multicolumn{5}{|c|}{ BMI kg/m2 } \\
\hline$>30$ & 24 & 140.32 & 64.23 & \multirow[t]{2}{*}{0.443} \\
\hline$<30$ & 50 & 129.28 & 56.81 & \\
\hline \multicolumn{5}{|c|}{ Hypertension } \\
\hline yes & 35 & 123.25 & 57.65 & \multirow[t]{2}{*}{0.164} \\
\hline No & 39 & 142.61 & 60.45 & \\
\hline \multicolumn{5}{|l|}{ Smoking } \\
\hline Yes & 38 & 137 & 69.35 & \multirow[t]{2}{*}{0.603} \\
\hline No & 36 & 129.72 & 47.75 & \\
\hline
\end{tabular}

Effect of age, gender, BM I, hypertension , and smoking on fasting glucose value

and $44.12 \%$ had raised FBS values. Among non diabetics FBS was raised in $35 \%$ of cases. Diabetic patients had multiple riskfactors.

There was no significant effect of age, gender,smoking, BMI, hypertension on fasting blood glucose values.

In our study the mean concentration of HDL cholesterol and triglycerides were not significantly affected by age, gender, BMI, diabetes mellitus, hypertension and smoking. However mean LDL cholesterol levels were found to be significantly increased in male gender $(p=0.04)$, and in patients with $B M I>30 \mathrm{mg} / \mathrm{m} 2(p=0.014)$. Total cholesterol level was not found to be affected by age, gender, diabetes mellitus, hypertension and smoking. But it significantly increased when $\mathrm{BM} 1>30 \mathrm{mg} / \mathrm{m} 2$.

Prevalence of hypercholesterolemia, hypertriglyceridemia and low HDL cholesterol was $82.4 \%, 77 \%$ and $78 \%$ respectively. Comparison between males and females revealed significant difference only in total triglyceride level $(p=0.013)$.

\section{Discussion:}

CVD's cause 1.7-2.0million deaths annually in India. ${ }^{2}$ India has a higher number of people with diabetes than any other country in the world. By 2025 the countries with largest number of diabetes will be in India, China and US. $52 \%$ of cardiovascular deaths occur below age of 70 , compared to $23 \%$ in developed countries. ${ }^{11,12}$ Based on modelled estimate by WHO, a marked rise of diabetes related burden is expected in near future. ${ }^{13}$ The International Federation of Diabetes estimates the number of people with diabetes for 2003 and 2025 to be 194 million and 334 million respectively. In association with increasing diabetes prevalence, it inevitably increases the proportion of deaths from cardiovascular diseases in these countries as well as the consequence of diabetes. ${ }^{14}$

In a case control study in young north Indian patients clustering of hyperinsulinemia and impaired GTT was seen along with dyslipidemias. ${ }^{15}$ The high prevalence of glucose intolerance and a lipid pattern of reduced concentrations of HDL cholesterol and high concentration of triglycerides and abdominal obesity are characteristics of urban adult in India. ${ }^{11}$

Gupta R et al demonstrated a persistent high prevalence and increasing non-HDLcholesterol and

Triglycerides over a period of 8years in India in Jaipur Heart Watch -5 study. ${ }^{9}$ Our study showed increased triglycerides in AMI patients in age group of more than 50 years. Our study compare well with the baseline levels of lipids reported in other study. ${ }^{16}$ Increase in LDL cholesterol was seen more in males than in females. Estari $M$ et al ,observed dyslipidemia in $52.7 \%$ of men against $42.9 \%$ in women. ${ }^{17}$ Kadar in his study found $75.7 \%$ cases with dyslipidemia, with men greatly affected with hypertriglyceridemia than women. ${ }^{18}$

We found significant association of $\mathrm{BM} />30 \mathrm{~kg} / \mathrm{m} 2$ on values of total cholesterol level and LDL levels. $\mathrm{BM} 1>30 \mathrm{~kg} / \mathrm{m} 2$ is a major cardiovascular risk factor and often associated with raised BP, glucose intolerance, type 2 diabetes and dyslipidemias. ${ }^{4}$

Our study did not find any significant association between hypertension and lipid profile. Similarly diabetes mellitus also appears to have no significant effect on total 
cholesterol, HDL cholesterol and total triglyceride level in AM I patients. Swaminathan and co workers in their review concluded that South Asians have substantially higher rates of diabetes and coronary heart disease. An innate predisposition along with behavioural, traditional and environmental risk factors lead to insulin resistance and to diabetes and coronary vascular disease. ${ }^{19}$ Significantly higher BMI, abdominal obesity causes significant dyslipidemias and insulin resistance and also 3 fold increase in diabetes. ${ }^{20,21}$ In a large cohort study from Asia Pacific region, continuous association was found between the fasting blood glucose and cardiovascular disease. The associations were very similar for males and females. ${ }^{22}$ Kannel examined prospectively, in the Framingham cohort, the relation between the diabetes and impaired glucose tolerance with CVD. It was found that the incidence of CVD and risk factors were more in diabetic than in non diabetic men and women. Impact of diabetes on cardiovascular mortality and cardiac failure were more in women. Diabetes is a risk factor for several forms of CVD's. ${ }^{5}$ A study showed that markers of impaired insulin secretion and insulin resistance were independently associated with an increased risk of heart failure. ${ }^{23}$

$82 \%$ of our patients had hypercholesterolemia. Triglyceride level of $>100 \mathrm{mg} / \mathrm{dl}$ seen in around $77 \%$ of patients. Low HDL cholesterol seen in around $78 \%$ of patients. Low HDL cholesterol is the most common lipoprotein abnormality in patients with $\mathrm{CHD}$ and is predictive of $\mathrm{CHD}$ events, even when total cholesterol levels are normal. ${ }^{10}$

The National Cholesterol Education Programme recommends total cholesterol level $<200 \mathrm{mg} / \mathrm{dl}$ and LDL cholesterol $<100 \mathrm{mg} / \mathrm{dl}$ to be optimal. HDL cholesterol $<40 \mathrm{mg} /$ dl is a major risk factor for CHD. ${ }^{24}$

Our data confirms the previous observations that dyslipidemias is one of the major risk factor for CHD. We observed low HDL cholesterol and high triglycerides which are component of metabolic syndrome. 6 components of metabolic syndrome related to cardiovascular disease are identified by ATP111 which includes underlying risk factors for CVD are obesity, physical inactivity and atherogenic diet ; major risk factors are cigarette smoking, hypertension, elevated LDL cholesterol, low HDL cholesterol, family history of premature coronary heart disease (CHD), and aging; and the emerging risk factors include elevated triglycerides, small LDL particles, insulin resistance, glucose intolerance, proinflammatory state, and prothrombotic state. ${ }^{25}$ Kanjilal S and co workers concluded in their study that prevalence of MS varies amongst ethnic groups. Asian Indians are high at risk for CVD, diabetes, and their predispositions. ${ }^{26} \mathrm{BMI}$ of $23.32 \mathrm{~kg} / \mathrm{m}^{2}$ and higher was found to predict significant risk of metabolic syndrome in a study done by Pranitha \& co workers. ${ }^{27}$

A large international case control study (INTERHEART STUDY) reported that tobacco use, obesity with high waist:hip ratio, high blood pressure, high LDL cholesterol/low HDL cholesterol, abnormal apolipoprotein $A-1: B$ ratio, diabetes, low consumption of fruits and vegetables, sedentary lifestyles and psychosocial stress are 9 important risk factors/determinants of CVD which accounted for $>90$ per cent of population attributable risk of CHD globally. Two-thirds of this risk comes mainly from smoking and elevated Apo $B$ and Apo A ratio. ${ }^{28}$ The excess burden the excess burden of premature $C A D$ in Asian Indians may be due to genetic susceptibility mediated through elevated levels of lipoprotein (a), together with the lifestyle factors and changes in the diet. ${ }^{20,29}$ The association of polymorphism in the fatty acid binding protein and in the apolipoprotein C-111 was noted in study on Chennai urban population by Guittier et al. ${ }^{30}$

In conclusion, our study highlighted the prevalence of dyslipidemias associated with myocardial infarction but not significant impact of fasting glucose levels.

Given the multifactorial nature of CVD, no single solution will be applicable to all geographic and economic regions of the world. However risk factor reduction done by implementing public health measures, targeting high risk subgroup of population that will benefit most from cost effective preventive measures and finally by giving higher cost treatments. ${ }^{31}$ 


\section{Acknowledgement:}

I thank Soumya Shetty for the statistical analysis of this study.

\section{References:}

1. Leeder SR, Raymond SU, Greenberg H, Lui H, Esson K (2004) A Race Against Time: the Challenge of Cardiovascular Disease in developing economies. New York: The Centre for Global Health and Economic Development, Columbia University. Available:http://www.earth. columbia.edu/news/2004/images/raceagainsttime_FINAL_051104.p df (accessed online on 10/7/2013)

2. Jha P, Gajalakshmi V, Gupta PC, Kumar R, Mony P, et al.(2006) Prospective study of 1 million deaths in India: Rationale, design, and validation results. PLoSM ed 3(2): e18

3. World Health Statistics 2008. World Health Organisation, www.who.int/en/ (accessed online on 10/7/2013)

4. Global Atlas on Cardiovascular Disease Prevention and Control. M endis S, Puska P, Norrving B editors. World Health Organization (in collaboration with the World Heart Federation and World Stroke Organization), Geneva 2011

5. Kannel WB,,M cGee L. Diabetes and Glucose Tolerance as Risk Factors for Cardiovascular Disease: The Framingham Study. Diabetes Care M ARCH-APRIL 1979;(2): 120-126,

6. Wahab N, Cowden E, Pearce N, Gardner M, Merry H, Cox J. Is blood glucose an independent predictor of mortality in acute myocardial infarction in the thrombolytic era?. J Am Coll Cardiol. 2002;40(10):1748-1754

7. Brezinka V,Padmos I. Coronary Heart Disease Risk Factors in Women. Eur Heart] 1994;15:1571-84

8. Poultar.N. Global risk of cardiovascular disease. Heart 2003;89(Suppl II):ii2-ii5).

9. Gupta R et al.Persistent high prevalence of cardiovascular risk factors in the urban middle class in India: Jaipur Heart Watch-5. J Assoc Physicians India. 2012 Mar;60:11-6

10. Miller M. Raising an isolated low HDL-C level:Why, how, and when? CLEVELAND CLINICJOURNALOF M EDICINE 2003;70(6):553-560

11. Ghaffar A, Reddy KS, Singhi M. Burden of non-communicable diseases in South Asia. BM J. 2004 April 3; 328(7443): 807-810

12. Murray CJL, Lopez AD, eds. Global burden of disease. Harvard, MA: Harvard School of Public Health, 1996. (Vol 1of Global Burden of Disease and Injury series.)

13. King H, Aubert RE, Herman WH. Global burden of diabetes, 19952025: prevalence, numerical estimates, and projections. Diabetes Care. 1998Sep;21(9):1414-31.

14. Wild S, Roglic G, Green A, Sicree R, King H. Global Prevalence of Diabetes Estimates for the year 2000 and projections for 2030.Diabetes Care M ay 2004 vol. 27 no. 5 1047-1053

15. M isra A, Reddy RB, Reddy KS, M ohan A, BajajJS. Clustering of impaired glucose tolerance, hyperinsulinemia and dyslipidemia in young north Indian patients with coronary heart disease: a preliminary casecontrol study. Indian Heart J. 1999 M ay-Jun;51(3):275-80

16. Iqbal MP, Shafiq M, Mehboobali N, Iqbal SP, Abbasi K. Variability in Lipid Profile in Patients with Acute Myocardial Infarction from two tertiary care hospitals in Pakistan. I Pak Med Assoc. 2004 Nov;54(11):544-9
17. Estari $M$ et al.The investigation of serum lipids and prevalence of Dyslipidemia in urban adults" population of Warangal district, India. Biology and M edicine 2009; 1 (2): 61-65.

18. Khader YS et al : Prevalence of Dyslipidemia and its associated factors among Jordan adults. Journal of clinical lipidology2010; 4:53-58.

19. Swaminathan K, Mathanan A, Jebamani S. Diabetes and coronary artery disease in South Asians. The British Journal of Diabetes and Vascular Disease 2013 June. http://dvd.sagepub.com/content/carl /2013/06/10/14746514/3492177

20. Enas EA, Senthilkumar A. Coronary Artery Diease in Asian Indians; An update and review. Internet Journal of Cardiology 2001;1(2)

21. Singh RB, Bajaj S, Niaz M A, Rastogi SS, M oshiri M . Prevalence of type 2 diabetes mellitus and risk of hypertension and coronary artery disease in rural and urban population with low rates of obesity. Int J Cardiol. 1998Sep 1;66(1):65-72.

22. ASIA PACIFIC COHORT STUDIES COLLABORATION. Blood Glucose and Risk of Cardiovascular Disease in the Asia Pacific Region. Diabetes Care 2004:27:2836-2842

23. Ingelsson E,Arnlov],Sundstrom J, Zethelius J, Vessby B, Lind L. Novel M etabolic Risk Factors for Heart Failure. Journal of American College of Cardiology 2005;46(11):2054-60

24. (NCEP) National Cholesterol Education Program. Third report of the National Cholesterol Education Program expert panel on detection, evaluation and treatment of high blood cholesterol in adults (ATP-III) final report.Circulation. 2002;106:3143-421

25. Third report of the National Cholesterol Education Program (NCEP) expert panel on detection, evaluation, and treatment of high blood cholesterol in adults (Adult Treatment Panel III). Final report. Circulation. 2002; 106: 3143-3421.

26. Kanjilal S, Shanker J,Rao VS, Khadrinarasimhaih NB, Mukherjee M, lyengar SS, Kakkar VV. Prevalence and component analysis of metabolic syndrome: An Indian atherosclerosis research study perspective. Vasc Health Risk M anag. 2008 February; 4(1): 189-197

27. Kamble P, Deshmukh PR, Garg N. Metabolic syndrome in adult population of rural Wardha, central India. Indian J Med Res. 2010 December; 132(6): 701-705

28. Yusuf S, Hawken S, Ounpuu S, Dans T, Avezum A, Lanas F, et al. on behalf of the INTERHEART Investigators. Effect of potentially modifi able risk factors associated with myocardial infarction in 52 countries (the INTERHEART study): casecontrol study. Lancet. 2004;364:937-53

29. Joshi et al. Risk Factors for Early M yo cardial Infarction in South Asians Compared With Individuals in Other Countries. JAMA. 2007;297(3):286-294

30. Guettier JM, Georgopoulos A, Tsai MY et al. Polymorphisms in the fatty acid-binding protein 2 and apolipoprotein C-III genes are associated with the metabolic syndrome and dyslipidemia in a South Indian population.J Clin Endocrinol M etab 2005; 90: 1705-11

31. Grundy SM et al. Primary Prevention of Coronary Heart Disease: Guidance From Framingham : A Statement for Healthcare Professionals From the AHA Task Force on Risk Reduction. Circulation. 1998:97:1876-1887 